\title{
O espaço interno e inter-relações: apontamentos a partir do sistema LMA/BF
}

\section{The inner space and interrelations: notes from the LMA / BF system}

Flavia Pilla do Valle ${ }^{1}$

Cibele Sastre ${ }^{2}$ 


\section{Resumo}

Este ensaio textual discute a noção de espaço a partir do sistema LMA/BF. Como produzir uma relação ativa entre espaço e práticas corporais de dança? Que contribuição esse conhecimento agrega ao ator, bailarino, professor, coreógrafo e diretor de dança? O presente escrito aponta relações entre espaço interno e outros princípios e temas desse sistema, como respiração, forma fluida, arquitetura móvel e relação interno-externo. Conclui-se que espaço não pode ser visto como entidade isolada, mas, sim, por meio da relação que com ele se estabelece, relação esta que se constrói a partir de uma aproximação e percepção sensível de cada um.

Palavras-chaves: Espaço; espaço interno; Laban; LMA/BF; interno- externo

\section{Abstract}

This textual essay discusses the notion of space from the LMA / BF system. How to produce an active relationship between space and body dance practices? What contribution does this knowledge add to the actor, dancer, teacher, choreographer and dance director? The present writing points out relations between internal space and other principles and themes of this system, such as breathing, fluid form, mobile architecture and internal - external relationship. It is concluded that space cannot be seen as an isolated entity, but, rather, through the relationship that is established with it, which is built from an approach and sensitive perception of each one.

Keywords: Space; internal space; Laban; LMA/BF; internal- external

E-ISSN: 2358.6958

\footnotetext{
${ }^{1}$ Profa. Dra. Universidade Federal do Rio Grande do Sul (UFRGS) - flavia.valle@ufrgs.br

2 Profa. Dra. Universidade Federal do Rio Grande do Sul (UFRGS) - cibele.sastre@gmail.com
} 
Iniciar um texto sobre "espaço" é percebê-lo necessariamente acompanhado por um corpo e sua complexidade. É também a partir do corpo que estabelecemos e expandimos os limites entre o que está fora e dentro, re-considerando a máxima newtoniana da lei da impenetrabilidade e o princípio cartesiano de matéria como extensão: dois corpos não ocupam um mesmo lugar no espaço. Expandir tal máxima é, em certa medida, considerar o corpo como multiplicidade de sistemas perceptivos e sua(s) materialidade(s), bem como sua subjetividade. A dança é considerada uma arte espaçotemporal por relacionar-se simultaneamente com uma duração (cronológica e subjetiva) e com a presença de um corpo em movimento no espaço (físico e perceptivo). Podemos estabelecer relações espaciais em quaisquer lugares, pois a leitura e/ou percepção desse espaço não é necessariamente subordinada ao lugar, mas conjuga uma noção de corpo que é simultaneamente matéria e pensamento.

Produzir uma reflexão sobre corpo-espaço vem sendo uma prática na produção de conhecimento em dança, especialmente entre estudiosos da Análise do Movimento, fundada por Rudolf Laban (1879-1958) e sua colaboradora Irmgard Bartenieff (1900-1981). Esta análise, que fundamenta a expressividade do movimento e suas correlações psicofísicas, alia a percepção do corpo - como um "eu" - aos conhecimentos científicos biomédicos e das ciências humanas. Laban nos diz, por exemplo, que o espaço é o aspecto invisível do movimento, enquanto o movimento torna o espaço visível (Laban, 1966). Ele também nos diz que o espaço nunca está vazio. Há sempre matéria em movimento no espaço, seja o oxigênio e os gases invisíveis, ou os átomos de uma parede de concreto.

O espaço ao qual nos referimos neste texto pode se tornar compartilhável por diferentes parâmetros a serem utilizados no contexto labaniano, mas parte de um princípio fundamental, que é um constante trânsito entre componentes intra-entre-extra-corporal. Com Hubert Godard, vale dizer que espaço é sempre um espaço de ação, ou um espaço imaginário de ação (apud Mchose, 2006). Godard nos convida a pensar o espaço a partir de três aspectos: a história pessoal do ator-bailarino, a expectativa de cada um em relação a um espaço que já desenha rastros do movimento corporal conotado pela expectativa, e a noção de espaço de cada cultura ou contexto. Nesse sentido, espaço é a expectativa que temos dele, com a qual operamos corporalmente, com a singularidade de nossa história, nossa ação.

Vejamos como Modinger et al. (2012) nos ajudam a olhar para o espaço em outros campos da arte, na perspectiva da educação: no desenho, uma arte predominantemente espacial, folhas de papel são o suporte minimamente necessário para estabelecer relações entre lápis/tinta e a folha de modo a produzir uma imagem. Na música, arte predominantemente temporal, é possível estabelecer percursos de ondas sonoras ou imagens abstratas de percursos sonoros amalgamando a chamada quarta dimensão (tempo-espaço). Nas artes da cena, frequentemente e tradicionalmente usa-se o teatro - a caixa preta - como lugar no qual se estabelece a distinção entre público e artistas, separando-os especialmente numa relação frontal - considerando a arquitetura do palco italiano. Nesse caso, o espaço de ação de uma cena pode transformar completamente o lugar em um espaço composto por palavra e ação/movimento, que é uma condução à imaginação. 
Assim sendo, como produzir uma relação ativa entre espaço e práticas corporais de dança? Que contribuição esse conhecimento agrega ao ator, bailarino, professor, coreógrafo e diretor de dança? Rudolf Laban ajuda a traçar alguns caminhos.

\begin{abstract}
Varaljai vereknyei esliget falyi Laban Rezso Keresztelo szent Janos Attila, ou Rudolf Laban, como mais tarde ficou mundialmente conhecido, começou seu trabalho de pesquisa e criação na Europa, no início do século XX. Seu carisma, senso de humor, dedicação e entusiasmo, aliados à sua intuição, avidez intelectual e observação, fizeram dele não somente um grande 'mestre' da dança, mas uma pessoa muito querida e admirada por seus contemporâneos. (Marques, 2011, p.277).
\end{abstract}

Rudolf Laban desenvolveu um aprofundado trabalho que "apresenta, desde suas origens, um fecundo pensamento sobre a arte dramática" (Andrade, 2008, p.169). Seus estudos sobre o espaço são referência na dança e nas artes, que, para ele, inclui dança-som-palavra organizados em torno de uma dramaturgia. Esses estudos foram, num primeiro momento, intitulados Choreutics ${ }^{3}$ e hoje em dia incorporam um sistema mais amplo conhecido como LMA/BF (Laban Movement Analysis / Bartenieff Fundamentals). Esse é o termo adotado prioritariamente neste texto, pois, apesar de reconhecermos a enorme contribuição de Laban nesses estudos, é preciso do mesmo modo admitir que houve e há inúmeros colaboradores que fomentam e ajustam o sistema continuamente. Assim, a LMA/BF está em constante atualização4.

LMA/BF é um sistema que envolve a observação, a análise e a descrição dos movimentos corporais a partir de quatro categorias ${ }^{5}$ interligadas: Corpo (o que se move), Expressividade ou Esforço (como se move), Espaço (onde se move) e Forma (com quem se move ou o envolvimento em geral). Este texto discute a noção de espaço a partir da categoria Espaço em LMA/BF e sua relação interno-externo, articulado com outros conceitos inerentes a outras categorias, como respiração (categoria Corpo), forma fluída (categoria Forma) e arquitetura móvel (categoria Corpo). Acredita-se que, com uma compreensão desse "onde" o ator-bailarino se move e como ele produz o espaço, pode-se ter então um maior aprofundamento do trabalho corporal nas artes da cena.

\title{
Os espaços do espaço: subdivisões
}

Em LMA/BF, o Espaço é o meio, infinito, onde o corpo existe. Tal qual Laban destaca como o primeiro fator da relação espaço e movimento, "[...] inúmeras direções radiam do centro do nosso corpo e sua cinesfera para o espaço infinito" (Laban, 1966, p.17, tradução nossa) ${ }^{6}$. Laban estava interessado na divisão do espaço infinito em pontos, linhas, planos, direções e formas identificáveis. Nesse sentido, o sistema

\footnotetext{
3 Este estudo teve uma publicação posterior à morte do autor, em 1966 na Grã-Bretanha, a partir dos manuscritos entregues a Lisa Ullman. Eles foram entregues primeiramente por Laban aos cuidados de Leonard e Dorothy Elmhirst em 1940 quando o Departamento de Artes de Dartington Hall foi fechado por causa da guerra. Posteriormente, este livro ganhou uma edição americana sob o nome The Language of Movement: a guidebook to choreutics.

4 Importante dizer que a formação das autoras se deu na escola de Nova York fundada por Irmgard Bartenieff nos anos 1960, que aliou seus estudos em fisioterapia aos estudos realizados com Laban na Alemanha e na Inglaterra.

${ }^{5}$ As quatro categorias são, por convenção, descritas com letra maiúscula: Corpo, Expressividade/Esforço, Forma, Espaço (BESS).

${ }^{6}$ No original: Innumerable directions radiate from the centre of our body and its kinesphere into infinite space.
} 
divide o espaço em três tipos: o espaço geral ou global, o espaço individual ou cinesfera e o espaço interno.

O espaço geral ou global é o espaço que fica além do corpo em extensão máxima. Nas artes da cena, o espaço global pode ser pensado como sendo a sala de ensaio, o palco italiano, uma arena, uma semiarena ou a rua, ou seja, o lugar em que ocorre a performance. Pensar esse espaço nas artes da cena é de suma importância, pois é a partir desse formato que se dá a apreciação do público e se estabelece a relação palco-plateia. Envolve não só pensar a disposição do cenário e dos elementos cênicos, mas também a relação que os corpos estabelecem com o público em tal ambiente. Como os corpos dos atores-bailarinos desenham as trajetórias dos deslocamentos? Que rastros imaginários são desenhados? Como eles se colocam em relação um ao outro? Que formações (lineares, em colunas, circulares, triangulares, conglomerados tipo "cardume"...) são capturadas por nossa percepção visual?

O espaço individual ou cinesfera é o espaço de uma bolha imaginária em volta do corpo de cada um. É definida como "[...] a esfera ao redor do corpo, cuja periferia pode ser alcançada por membros facilmente estendidos, sem se deslocar daquele lugar que é o ponto de apoio quando se está em pé sobre um pé, a que podemos chamar de 'lugar'" (Laban, 1966, p.10)․․ Essa esfera imaginária pode ser reconfigurada por acentos espaciais que formam polígonos. Esses polígonos, conhecidos também como cristais, são formados de superfícies planas equiláteras e idênticas, unidas por seus lados. Os polígonos ou cristais mais utilizados como referência são o tetraedro, o octaedro, o cubo e o icosaedro (ver figuras, abaixo). Tais figuras nos ajudam a visualizar as três dimensões, as diagonais, os planos e outros elementos. Assim, podemos também criar parâmetros para visualizar a amplitude dos movimentos na cinesfera, que podem ser de longo alcance (distais), médio alcance (mediais) ou curto alcance (proximais), tendo como referência o chamado centro do corpo. A cinesfera evidencia "onde" o movimento corporal mais visível acontece e, por isso, é de grande relevância ao estudo do movimento.

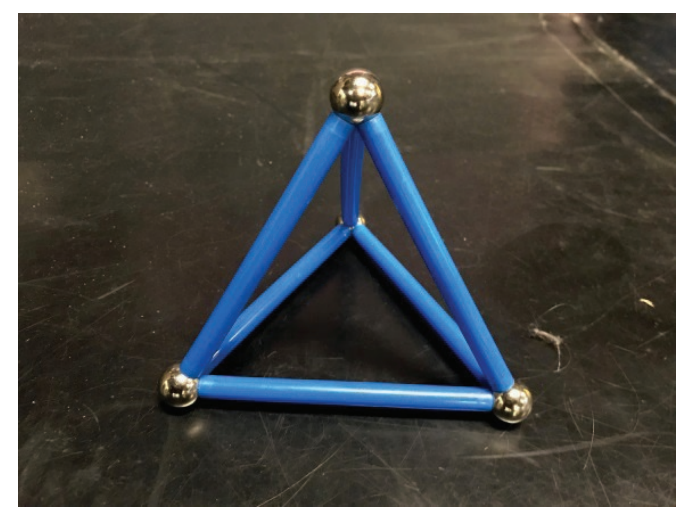

Figura 1 - Tetraedro, representando as quatro categorias interligadas do sistema. Foto das autoras.

\footnotetext{
${ }^{7}$ No original: The kinesphere is the sphere around the body whose periphery can be reached by easily extended limbs without stepping away from that place which is the point of support when standing on one foot, which we shall call the "stance". (Tradução nossa).
} 


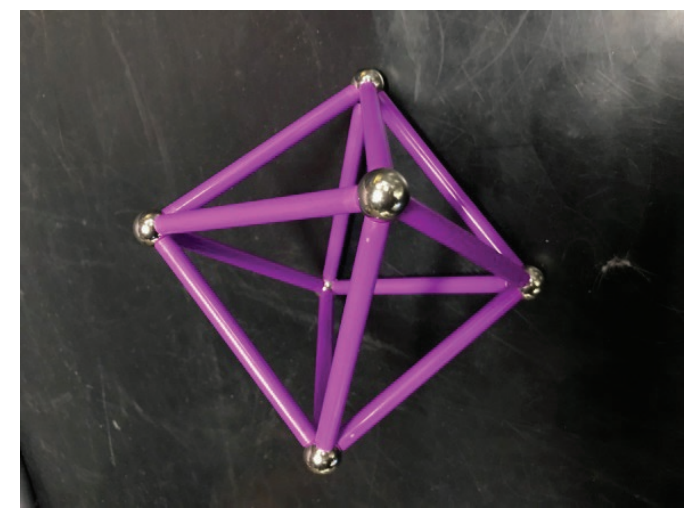

Figura 2 - Octaedro, que emerge da cruz das três dimensões. Foto das autoras.

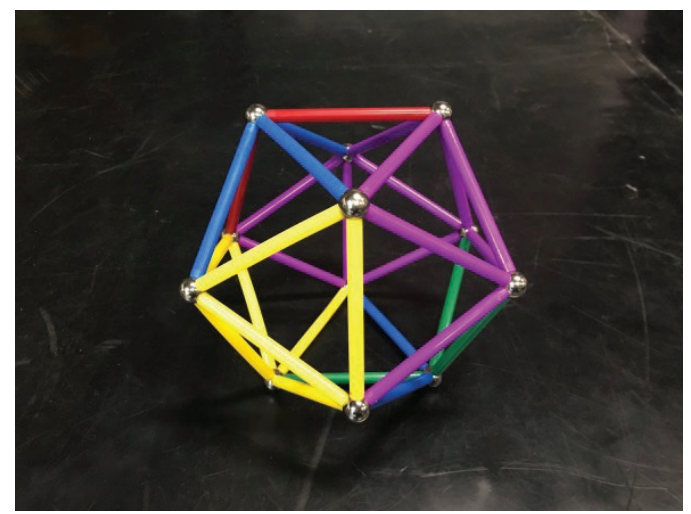

Figura 3 - Icosaedro, que emerge dos três planos vertical, horizontal e sagital. Foto das autoras.

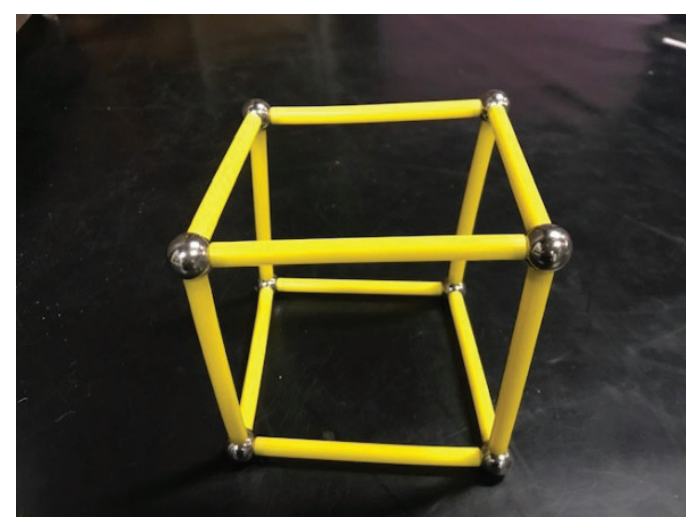

Figura 4 - Cubo, que é a referência para as quatro diagonais. Foto das autoras.

Este texto se detém, porém, num espaço de percepção mais sutil, que é o espaço interno. O espaço interno é o espaço de dentro do corpo. Ele é constituído por nossos músculos, ossos, líquidos, órgãos, ar e demais sistemas, bem como nossas subjetividades em relação ao nosso pensamento. Ele é maleável fisicamente, principalmente no torso, energicamente no todo. A figura da Banda de Moebius, criada pelo astrônomo e matemático August Ferdinand Moebius e amplamente utilizada por Laban, Lacan, e muitos dos colaboradores de ambos, é representativa da ideia maleável e transitória da noção do que está dentro ou fora, a depender do ponto de vista que se tem no percurso da fita, conforme figura que segue. 


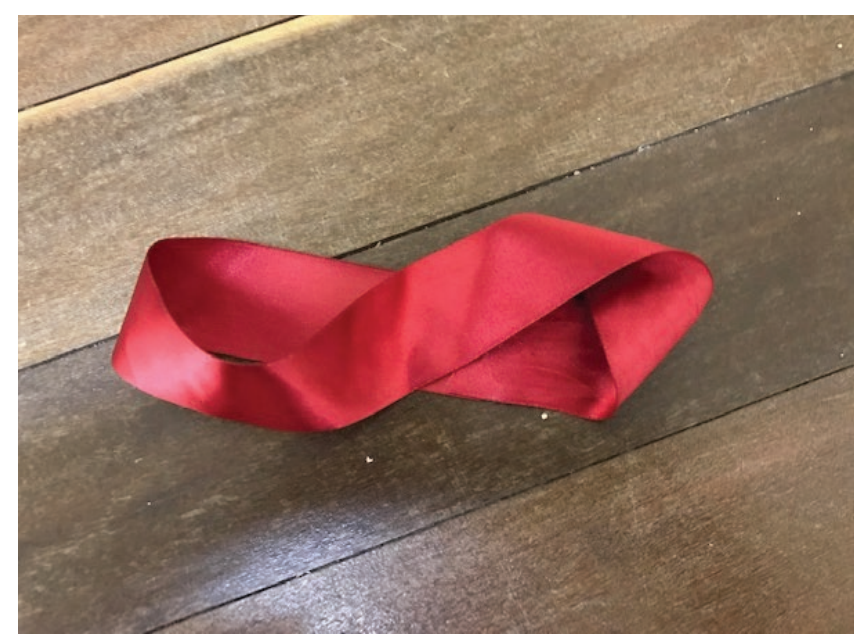

Figura 5 - Banda de Moebius. Foto das autoras.

\section{O espaço interno e a respiração}

A respiração como suporte para o movimento é um dos Princípios de Movimento, que integra a categoria Corpo, sistematizados por Irmgard Bartenieff ${ }^{8}$. Ela também está presente na categoria Corpo como um dos seis padrões de desenvolvimento (outro princípio), a partir da ideia de respiração celular, em que respirar é nutrir cada célula com o processo de oxigenação.

Nada é mais impressionante do que observar na imobilidade absoluta, alheio a toda a intervenção voluntária, o movimento profundo que persiste no nosso interior: a subida e a descida do diafragma como uma onda que dilata e contrai alternadamente a caixa torácica. [...] o corpo como passagem, como parede porosa entre dois estados do mundo, e não como massa opaca, plena e impenetrável. (Louppe, 2012, p.91-92).

A respiração talvez seja o elemento mais familiar na alteração do espaço interno. Aumentamos nossa cavidade torácica ao inspirar e a diminuímos ao expirar. Esse aumento e diminuição da caixa torácica, entretanto, pode ter diferentes ênfases espaciais. Irene Dowd nos orienta sobre a disponibilidade de uso de variados modos de respiração.

Torna-se claro que grande parte do valoroso conselho que nos é dado sobre respiração é muito útil desde que usado no todo simultaneamente. A absorção do oxigênio é aumentada quando se usa a 'respiração do peito', assim como a 'respiração abdominal', respiração 'das costas', 'originada da pelve', e enfim 'através do torso inteiro'. (Dowd, 1995, p.15). ${ }^{9}$

\footnotetext{
${ }^{8}$ Os Princípios de Bartenieff variam em seu número e tradução dependendo dos autores. Alguns autores optam por sobrepô-los devido à intensa inter-relação existente. Outros trabalham com a ideia de que alguns deles são conceitos relacionados. Aqui citaremos, para fins de informação complementar, todos os Princípios de Movimento e conceitos relacionados: Suporte da Respiração; Suporte Muscular Interno (ou Suporte Central); Alinhamento Dinâmico (ou Conexão Ósseas ou Dinâmica Postural); Transferência de Peso; Iniciação e Sequenciamento; Intenção Espacial; Motivação Expressiva; Fator de Rotação; Padrões de Desenvolvimento (ou Organização Corporal); Enraizamento (ou Ancoramento); Correntes Cinéticas (ou Correntes do Movimento); e Contratensão.

${ }^{9}$ No original: It becomes clear that much of the valuable advice on breathing given us is quite useful as long as it is all used simultaneously. Oxygen intake is increased when we use "chest breathing" as well as "abdominal breathing", breathing "from the back", "from the pelvis", and indeed "through the whole trunk. (Tradução nossa)
} 
Em diferentes práticas somáticas existem orientações sobre como "aprender a respirar". Dowd (1995) nos diz que, na dança, raramente somos alertados sobre possíveis usos da respiração e, geralmente, quando a orientação nos chega, é por meio de uma restrição, como fechar as costelas para não aparecer o movimento de respiração, ou para manter-se com peito alto como se estivéssemos constantemente inspirando. Pensar na respiração durante um movimento de dança pode ser extenuante, causando o efeito contrário do que uma atenção mais aprofundada pode trazer para a performance de qualquer ator-bailarino. Ao aprender a tomar o ar pelas diferentes partes mencionadas por Dowd, liberamos a fluência dos movimentos no corpo, sobretudo porque o torso mantém sua mobilidade, ativando as conexões entre distintas partes do corpo.

Diferentes técnicas de respiração disponibilizam diversos modos de respirar. A riqueza dessa diversidade está na maior amplitude de movimentos que o torso adquire, se pensarmos que, ao movimentarmos nosso corpo, o torso se molda a cada um desses movimentos. Não podemos pensar em um só modo de respirar se o corpo está em constante movimento na dança. Tal qual Louppe (2012, p.93) chama a atenção "a dança contemporânea nunca fixou um método respiratório como tal".

A respiração moldada pelo espaço interno é, assim, essencial para a eficiência e fluência dos movimentos. Incentivar momentos de atenção, tanto de expiração como de inspiração mais ativa nas partituras de movimento, torna-se uma ferramenta para otimizar o trabalho corporal do ator-bailarino. A inspiração ajuda a suspender o corpo, reforçando a ideia de leveza proposta pela técnica.

A prática (informada) da respiração prende-se com as necessidades e as qualidades de movimento. Por vezes, é o movimento que revela a respiração interior da qual é a face visível: o lançamento (de véus, de objetos), vertente funcional do ímpeto, permitiu a Dalcroze, tal como a Humphrey em Soaring (1920), tornar visível o impulso da respiração. (Louppe, 2012, p.94).

Valle (2004, p.56) destaca que "apesar das ênfases dadas às diversas técnicas corporais, a respiração acontece no equilíbrio da inspiração e expiração". O fluxo respiratório, portanto, é essencial ao ator-bailarino, pois se a inspiração pode ajudar certas qualidades de movimento, a expiração também tem seu papel. Louppe destaca a atenção dada por Dominique Dupuy à fase expiratória, ele traça uma relação entre o diafragma e o peso, pois “[...] o levantamento de peso, a pressão e o aperto na torção, tal como as acções que obrigam o corpo a baixar-se e dobrar-se, retraem os filtros interiores" (2012, p.97).

Na dança moderna de Martha Graham, fundamentam-se mudanças corporais que acontecem no decurso entre a expiração e a inspiração, no qual se desenvolvem os princípios de contração e relaxamento e todo um vocabulário decorrente deles. Sobre isso, Anderson (1992, p.177) ${ }^{10}$ diz: “[...] apesar de o balé clássico frequentemente procurar ocultar o esforço, Graham revelava-o, persistindo em mostrar as contrações e atingir intensidade arrebatadora na crença de que a vida por si só é um esforço".

\footnotetext{
10 No original: Whereas classical ballet often sought to conceal effort, Graham revealed it, allowing contractions to attain whiplash intensity in the belief that life itself is effort. (Tradução nossa)
} 
Um dos componentes dos princípios fundamentais de Bartenieff, o suporte respiratório, é base para o princípio das correntes cinéticas, que são definidas como a ativação da faísca muscular, que se desenrolará passando entre os grupos musculares, numa perfeita orquestração e harmonia. As correntes cinéticas, por sua vez, ajudam a conexão do corpo.

Fernandes (2006, p.53) nos diz que "[...] a grande maioria dos movimentos ocorre na expiração, aproveitando-se o impulso do músculo iliopsoas [...] para desencadear movimento e conectar diferentes partes do corpo". Bartenieff nos indica que o músculo iliopsoas conecta a metade superior do corpo à metade inferior, operando também na mobilidade dos membros inferiores. Isso se dá por meio do uso de músculos que compreendem o princípio do suporte muscular interno, ou seja, além dos músculos abdominais, iliopsoas, quadrado lombar e diafragma, com contribuição dos músculos profundos do quadril, que mobilizam o fêmur. "Esse suporte mobiliza toda transferência de peso corporal, desde a simples flexão coxofemoral até a mudança de nível, sentando, levantando, caminhando, interagindo com espaço tridimensional e de volta ao chão" (Fernandes, 2006, p.53).

Se respirar nos permite interagir com o espaço tridimensional por meio das correntes cinéticas que compreendem o princípio do suporte muscular interno, ao mesmo tempo nos proporciona diferentes atmosferas, ou humores pessoais. Por exemplo, deprimir a caixa torácica e empilhar grande parte de nossa massa corporal, encolhendo o corpo para baixo, pode ser relacionado a um estado depressivo ou que minimize a relação com o ambiente externo, proporcionando um estado mais introspectivo. Quanto maior a mobilidade dada ao torso para a entrada e saída de ar durante o processo respiratório, maior será tanto a assimilação de oxigênio no corpo, quanto seu efeito de oxigenação celular, produzindo energia para novas relações espaciais na cinesfera, podendo levar inclusive a um estado de êxtase.

\title{
O espaço interno e a forma fluída
}

A Forma é uma das quatro grandes categorias do sistema da labanálise, juntamente com o Corpo, a Expressividade/Esforço e o Espaço. Ao mencionar que a Forma sinaliza com quem se move, isso é dizer que há um nível de interação mais proeminente nessa categoria, seja com pessoas, objetos, animais, reais ou virtuais, ou o ambiente em si. Hackney $(2002$, p.43) elucida que:

\begin{abstract}
Uma intenção em Forma pode incluir moldar o corpo para revelar uma forma particular (por exemplo, um coreógrafo pode escolher uma forma arredondada fechada, uma forma de bola, para representar alguém que está virando para dentro); ou mudando a forma do corpo para trazer um relacionamento específico com outras pessoas ou com o ambiente (usando uma forma direcional linear falada ao ir em direção a um objetivo, por exemplo); ou revelar um investimento no processo de mudança de forma (subindo quando feliz, recuando de medo, etc.). ${ }^{11}$
\end{abstract}

\footnotetext{
11 No original: An intent in Shape might include forming the body to reveal a particular "shape" (for instance, a choreographer might choose an enclosed rounded form, a ball shape, to depict someone who is turning inward); or changing the form of the body to bring a specific relationship to other people or the environment (using a spoke like directional shape change when going toward a goal, for example); or reveal an investment in the process of shape change (rising when happy, retreating in fear, etc.). (Tradução nossa)
} 
Essa categoria, assim como a categoria Espaço, também se subdivide em três modos de transição de forma: forma fluida, forma direcional e forma tridimensional ou esculpida.

Um aspecto a destacar nessa trifurcação é o diferenciado grau de interação ou envolvimento, conforme já mencionado. Na forma tridimensional ou esculpida, o corpo estabelece uma relação com o volume espacial que ocupa um corpo ou objeto imediatamente ao seu redor, ou seja, está voltada para fora, para o ambiente ou para o(s) outro(s). Já na forma fluida, é na relação que o corpo estabelece entre suas próprias partes que se deposita a atenção da análise. Crescer e encolher são palavras - chave para a percepção/observação dessa relação do corpo e suas partes, dirigindo atenção mais para si próprio e para o interior.

$\mathrm{Na}$ forma direcional, se defende que há uma ponte entre este estado voltado para si e o estado voltado para o ambiente, por meio de uma relação bidimensional/ linear corpo-espaço. Essas diferenças são sutis e merecem estudo aprofundado de cada modo de transição de Forma para uma experiência perceptiva mais produtiva. Mas é certamente pelos modos de transição de Forma que podemos adentrar nas singularidades das relações corpo-espaço.

Retomando os três modos de transição de Forma, tal qual o próprio nome diz, a forma tridimensional ou esculpida aborda o espaço tridimensional ${ }^{12}$ da cinesfera. Podemos pensar essa tridimensionalidade como volume em movimento. Volume envolve uma medida tripla: altura, profundidade e largura. O movimento de cavar o espaço em volta de si com partes do corpo ou corpo inteiro pode ser uma imagem que ajude a entender essa tridimensionalidade, tanto quanto o moldar-se a um corpo ou objeto real ou virtual, em sua tridimensionalidade. Aqui podemos traçar uma relação com o espaço absoluto de Wigman, pois

[...] trata-se de um espaço que o corpo encara como um outro corpo, um espaço como parceiro, se souber dominar seus espaços tensionais, pode inventar consistências e esculpi-las (o carving space de Laban, que se inicia com a modelagem do espaço de proximidade). (Louppe, 2012, p.189).

Por envolver movimentos que exploram largura, altura e profundidade simultaneamente, o espaço tridimensional vai utilizar um princípio de movimento associado à categoria Corpo que se chama fator de rotação, em que se usa o potencial das articulações do corpo - principalmente das articulações da coluna, coxofemoral e escápulo-umeral - para moldar-se ou encurvar-se. Esse princípio é chamado por Fernandes (2006, p.69) de rotação gradual.

A rotação gradativa consiste numa corrente neuromuscular de movimento que permite ao corpo traçar caminhos arredondados, suavizando quedas e mudanças de direções, facilitando sua projeção no espaço tridimensional. Este princípio implicaria no total uso dos músculos transversais e profundos que permitiriam a rotação das articulações (ombros, coxofemural, coluna) com movimento tridimensional e total rotação do corpo ao redor de seus eixos.

\footnotetext{
12 Se diz mais tridimensional porque sempre somos tridimensionais e vivemos num mundo tridimensional. Ao se falar em análise de movimento se entende que há uma ênfase que pode ser tridimensional.
}

Flavia Pilla do Valle

Cibele Sastre 
Já a forma direcional vai abordar o espaço mais bidimensional ou unidimensional. De acordo com a LMA/BF, os movimentos bidimensionais são realizados nos planos da 'porta', 'mesa' e 'roda'13. Os movimentos em uma dimensão referem-se às linhas básicas vertical, horizontal e sagital que se cruzam no cento de cada corpo, centro este entendido no sistema como a região do umbigo ou um pouco abaixo dele.

A forma fluida, tal qual mencionado, é mais voltada para si mesma.

A Forma Fluída implica no relacionamento do corpo consigo mesmo, entre suas partes; movendo-se a partir da respiração, voz, órgãos e líquidos corporais. O corpo está totalmente submergido em si mesmo, em seu volume criado pela inter-relação de seus componentes. É o caso de um bebê que ainda não reconhece objetos ou pessoas, nem procura pegá-los, mas encontra-se diluído em suas sensações, instintivamente chupando o dedo ou a mão. No adulto, a Forma Fluída pode estar presente subliminarmente, como suporte respiratório e dos órgãos internos na execução de qualquer movimento, ou mais evidente, como ao balançar-se para dormir, mexer no cabelo numa atitude de autocarícia, ou apenas suspirando. (Fernandes, 2006, p.161).

Esses movimentos subliminares são movimentos de ajuste ou sombra, movimentos sutis, de certas partes do corpo em relação a outras.

Os movimentos de sombra nos relatam o andamento de tais processos interiores e boa parte dos movimentos mais característicos de uma pessoa são aqueles por ela realizados inconscientemente, os quais precedem, acompanham ou são a sombra de ações planejadas. O indivíduo pode se coçar, esfregar o queixo, apertar o nariz, sacudir ou contrair os dedos, ou ainda executar outros gestos vagos, destituídos de significação prática definitiva, realizados apenas pelos movimentos em si. (Laban, 1978, p.169).

Como outros exemplos de movimentos de ajuste ou de sombra podemos pensar também reacomodar-se em uma cadeira, avançar o torso para melhor prestar atenção em algo, ou recuar. Eles emitem informações subliminares sobre a relação do corpo com o ambiente por meio da relação entre as partes. Eles fazem parte da forma fluida, cujas palavras - chave são crescer e encolher.

Crescer ou encolher são ações corporais que podem ser diretamente relacionadas, também, com a respiração. Um suspiro longo pode nos fazer crescer e ampliar o espaço que o corpo estava ocupando até então. Encolher pode recolher a intensidade da presença física do corpo no espaço. Essas ações podem acontecer no corpo não apenas em altura, mas podemos crescer para os lados ou na dimensão sagital (frente-trás), mesmo quando encolhemos a parte da frente, por exemplo, para crescer a parte de trás do torso ou vice-versa, trabalhando com formas côncavas e convexas. Componentes subjetivos são redimensionados em relação ao ambiente de acordo com a amplitude da relação:linear, bidimensional ou tridimensional. Não há como destacar significados para cada atitude de crescer ou encolher nas diferentes

\footnotetext{
${ }^{13}$ Respectivamente, plano Vertical (altura e largura), Horizontal (largura e profundidade) e Sagital (profundidade e altura).
} 
dimensões, pois o sentido do movimento exige contextualização sempre. Ao combinarmos informações relativas às quatro categorias de análise, é possível inferir algum sentido ao movimento, conquanto se possa ter acesso ao contexto em que ocorre.

Quando definimos o sistema LMA/BF composto por quatro categorias interligadas dizemos que há uma categorização para fins de organização das ideias, mas que essas ideias estão sempre atuando em conjunto. Falamos sempre de um corpo que se move no espaço com certa qualidade expressiva e uma interação. Certas vezes um aspecto fica mais proeminente ao olho do observador, mas o movimento é um todo interligado. Assim, espaço interno (Espaço) tem estreita relação com forma fluida (Forma), que tem uma estreita relação com o suporte respiratório (Corpo), que por sua vez tem uma estreita relação com o Fluxo ou Fluência (Expressividade). Fluxo é um dos quatro fatores da Categoria Esforço ou Expressividade do sistema. Ele pode ser livre ou controlado/contido/interrompido. Observar e/ou perceber a fluência do movimento nos possibilita associar este fator com o modo como utilizamos nossa respiração como suporte para essa continuidade, ou para a interrupção ou controle do movimento, podendo gerar ajustes corporais relativos à forma fluida que informa a conexão interior-exterior da relação corpo-espaço. Isso mostra, novamente, como as categorias operam simultaneamente, trazendo informações distintas e congruentes sobre diferentes aspectos.

\title{
O espaço interno e a arquitetura móvel
}

\begin{abstract}
Quando desejamos descrever uma única unidade de movimento espacial, podemos adotar um método semelhante ao de um arquiteto ao elaborar um edifício. Ele não pode mostrar todas as visões internas e externas em apenas um rascunho. Ele é obrigado a fazer uma planta e pelo menos duas elevações, transmitindo assim à mente uma imagem plástica do todo tridimensional. 0 movimento é, por assim dizer, arquitetura viva - vivendo no sentido de mudar de lugar e de mudar a coesão. Essa arquitetura é criada por movimentos humanos e é composta de caminhos que traçam formas no espaço, e isso podemos chamar de 'rastros da forma'. (Laban, 1966, p.5). ${ }^{14}$
\end{abstract}

Laban fez inúmeras relações com a arquitetura ao falar sobre o movimento corporal no espaço. As associações mais recorrentes são os polígonos imaginados no espaço pessoal que tornam palpáveis o infinito de linhas, pontos e direções espaciais que circundam e/ou desenham relações entre partes do corpo.

Outros princípios relativos à categoria Corpo que trazem relação direta com a visualização das linhas de movimento no espaço arquitetônico são as conexões ósseas, que proporcionam a visualização do movimento corporal a partir de seu esqueleto, num princípio chamado de alinhamento dinâmico ${ }^{15}$.

O alinhamento dinâmico envolve um constante processo de avaliação e ajuste de si. Tal qual o nome diz, é mais do que uma postura imóvel ereta na vertical. Barte-

\footnotetext{
14 No original: When we wish to describe a single unit of space-movement we can adopt a method similar to that of an architect when drafting a building. He cannot show all the inner and outer views in one draft only. He is obliged to make a ground-plan, and at least two elevations, thus conveying to the mind a plastic image of the three-dimensional whole. Movement is, so to speak, living architecture - living in the sense of changing emplacements as well as cohesion. This architecture is created by human movements and is made up of pathways tracing shapes in space, and these we may call "trace-forms". (Tradução nossa)

15 Outras traduções para Dynamic Alignment or Connectivity são Conectividade ou Dinâmica Postural.
} 
nieff (1980, p.21) nos conta que "a imagem dinâmica [de postura] é descrita por Laban como um processo tridimensional contínuo, coeso, que cria e recria uma série de relacionamentos de cima / baixo, direita / esquerda, frente / trás"16. Em movimento, quando uma parte do corpo se move, todas as outras partes se ajustam e as tensões provocadas no movimento estão sempre na busca de um equilíbrio dinâmico e instável. Essa instabilidade no trabalho do ator-bailarino promove paradoxalmente uma estabilidade por oposição de forças sempre em jogo, pois torna consciente o movimento e o deixa em estado de constante prontidão para o ajuste.

Portanto, pensar pontos, linhas, polígonos através de relações móveis entre eles é trabalhar a consciência da relação corpo-espaço. Uma dessas estratégias é pensar essas relações através de marcos ósseos específicos e como eles se arquitetam entre si em movimento. Por exemplo: a relação cabeça-cóccix nos movimentos que fazem o dorso ou a coluna se moverem em "c" - como uma linha móvel curva, que pode ocorrer tanto no plano sagital quanto no vertical, curvando frente e trás do dorso ou as laterais. Para isso, visualizar um retângulo que une os marcos ósseos das articulações escapulo-umeral e coxofemoral nos permite saber em qual dos planos a linha curva da coluna é desenhada. Também na conexão ísquios-calcanhares podemos visualizar outro retângulo que ajusta a distância entre os calcanhares com a distância entre os ísquios. Isso pode ser examinado em transferências de peso numa caminhada simples, dando visibilidade a um polígono imaginário móvel. Todos esses alinhamentos são conexões estabelecidas entre as partes do corpo ou marcos ósseos que estão em constante ajuste através da orquestração dos músculos que trabalham em perfeita sinergia.

Como efeito, desse trabalho corporal que relaciona diferentes marcos ósseos e coloca formas geométricas em movimento, tornando-as plásticas, emerge uma sensação de grande conectividade entre as partes do corpo. Um corpo (re)conectado produz outras dimensões na percepção de espaço interno. Mudar o eixo de um corpo é mudar um ponto de vista, uma perspectiva, um lugar de fala.

\section{Relação interno e externo}

Um grande tema ${ }^{17}$ que é recorrente na literatura disponibilizada por Laban é a constante relação interno - externo como um exercício de destacar as diferenças para integrá-las novamente. Peggy Hackney nos diz:

Polaridades estão sempre conosco e polarizações nos servem de forma muito útil em processos de diferenciação. Em estágios em que precisamos fazer distinções para crescer e progredir, é muito útil ter definições claras sobre opostos, para nos guiar e dar forma às nossas vidas. [...] O conceito de conectividade fica sem sentido se não há diferenciação. Polarização é parte da diferenciação. No entanto, se nunca nos movermos entre polaridades, vamos

\footnotetext{
${ }^{16}$ No original: The dynamic image is described by Laban as an ongoing, cohesive, three-dimensional process that creates and recreates a series of relationships of up/down, right/left, forward/backward.

17 LMA/BF apresenta quatro Grandes Temas por meio de aparentes polaridades. São eles Externo-Interno; Função-Expressão; Mobilidade-Estabilidade; Exaurição-Recuperação. Fernandes (2006) refere-se aos Grandes Temas como Temas de Contínua Dinâmica e Transformação
} 
nos sentir trancados e inaptos a sermos presentes por inteiro, como pessoa. (Hackney, 2002, p. 205). ${ }^{18}$

É assim que percebemos o quanto a noção de espaço não pode se restringir a algo distante de nosso espaço subjetivo, ou seja, de nossa noção de corpo. Se é por meio de nossas percepções que podemos distinguir e diferenciar, elas são integradoras do que produzimos com o que percebemos. A plasticidade do espaço, mobilizada pela incorporação dessa noção adquirida por meio de nossas percepções, ganha fôlego com a representação do espaço labaniano interno-externo, na já citada fita de moebius, onde o percurso faz transitar entre o que vemos como fora e como dentro. Hubert Godard nos ajuda a verificar esse tema com sua afirmação "Eu estou no espaço e o espaço está em mim"19 (retomando a relação espaço interno e respiração).

Considerando a relação entre o artista que dança sobre pressupostos da linguagem espacial labaniana e seu espaço de ação na cena, Louppe nos lembra: "[...] esta linguagem espacial como lhe chama Laban, tem de ser decifrada de modo diferente segundo cada artista, por vezes de acordo com cada obra" (2012, p.199). Ela segue dizendo que o espaço

[...] surge para alguns como a exteriorização da 'paisagem interior', espaço puramente poético cuja articulação com o espaço objetivo seria apenas um estado transitório, análogo a uma ressonância espacial imaginária e incapaz, a cada momento, de se actualizar completamente. (Louppe, 2012, p.199).

O espaço externo coloca imediatamente o corpo em relação. Assim, a percepção não se concentra unicamente num foco interno, mas administra, ao seu modo, as informações relacionadas ao ambiente, e os modos de relação com este. Os rastros de forma que a arquitetura do movimento imprime rapidamente no espaço carregam dois princípios de movimento frequentemente relacionados com os impulsos internos para o movimento: a motivação expressiva e a intenção espacial. A manifestação ou presença desses princípios já é, em si, a administração da relação interno-externo e a diferenciação entre o "eu e o outro", trazendo dinâmica expressiva para as relações rastreadas na cinesfera, tornando-a dinamosfera.

Louppe nos lembra, ainda, que Bartenieff trazia uma visão de corpo como uma "geografia das relações" através da qual, "nossa relação com o mundo se constrói, quer no plano afectivo, quer no plano poético" (Louppe, 2012, p.187). Isso retoma a relação espaço e forma, convidando-nos a observá-la como um "espaço de ação e inscrição de si" (Sastre, 2016, p.961), ou seja, um espaço que faz operar a geografia das relações. Aqui, as categorias Corpo e Espaço mostram-se amalgamadas em “[...] um campo generativo palpável, um tecido conjuntivo que se enlaça na experiência do próprio sujeito (Louppe, 2012, p.199). Como espaço, também, de produção de si, é bom lembrar a instabilidade das percepções e suas subjetividades, ou seja, que o

\footnotetext{
18 No original: Polarities are always with us and polar opposites serve us in a very useful way in the differentiation process. At a stage when we need to make distinctions in order to grow and progress, it is useful to have a clear definitions of opposites to guide us and give form to our lifes. [...]. The concept of connectivity is meaningless without differentiation. Polarization is part of differentiation. However, if we never move beyond polarity, we will feel "stuck" and unable to be present as a whole person. (Tradução nossa)

${ }^{19}$ Mchose (2006), subtítulo da entrevista realizada por Mchose com Godard para o artigo Espaço Fenomenológico.
} 
espaço-corpo está em constante transformação e que "não existem estruturas estáveis de suporte" (Miranda, 2008, p.56), mas um constante jogo móvel de relações transcorrendo esse tecido conjuntivo.

Para fins de estudo e reflexão compartilhados, cabe-nos objetivar um discurso capaz de produzir referenciais comuns na linguagem da dança, do corpo, do espaço, por meio da LMA/BF.

\section{Conclusão}

Pensar a relação externo-interno é um exercício de percepção do movimento corporal. Apesar de tal percepção pessoal ser valorizada - de modo que a experiência aconteça no corpo de cada um, há questões que podem ser compartilhadas no geral. Assim sendo, nesse exercício, todas as seções apresentadas anteriormente se relacionam ao grande tema interno-externo:

- a respiração é um processo que leva o ar do espaço exterior para o espaço interior;

- a forma fluida produz movimentos de ajuste que operam no espaço interno. A forma fluida, portanto, mais voltada para o interior, está sempre dando suporte aos outros tipos de Forma que ligam ou lidam com esta atenção ao ambiente exterior;

- a arquitetura do movimento pode ser pensada em termos de relações com estruturas geométricas que envolvem o corpo externamente, mas essas estruturas geométricas podem ser recriadas no espaço interno como polígonos que conectam marcos ósseos e operam por meio da ativação de suas conexões.

Laban, desde muito cedo nos seus estudos, já havia compreendido o espaço como uma força primordial no movimento corporal. Ele o tomou como objeto de estudo e percepção particularmente atenta. O espaço não pode ser entendido como uma entidade isolada, e sim como "[...] a nossa relação com o espaço, com todos os cambiantes e modos qualitativos que caracterizam essa relação" (Louppe, 2012, p.196).

Para as artes da cena é útil pensar com maior atenção no conceito do espaço, este sendo o "onde" a dramaturgia se desenrola. A ideia de espaço interno traz luz a mais uma faceta do trabalho corporal do ator-bailarino. Muitas ideias aqui traçadas são baseadas no sistema LMA/BF e muitas dessas relações estabelecidas ainda são pouco discutidas no contexto brasileiro e mundial. Este texto aborda inicialmente a perspectiva do espaço e traz a ideia do espaço interno para conectar outros conceitos do sistema.

Apresentamos as três principais subdivisões do espaço trazendo conceitos para esclarecer a perspectiva teórico-prática do sistema LMA/BF. Relacionamos o espaço interno (e externo) por meio da respiração, que internaliza matéria contida no ambiente, e devolve-a reprocessada. A depender das diferentes técnicas de respiração utilizadas para a prática de dança, pode-se encontrar diferentes formas de ajuste corporal e diferentes amplitudes de acomodação do torso, podendo ou não se estabelecer relações expressivas com estados anímicos a partir da função de crescer e encolher, entre os diferentes modos de transição de Forma. O tópico subsequente, portanto, abordou os modos de transição de Forma, aprofundando a relação do es- 
paço interno e a forma fluida. O texto seguiu fazendo uma relação do espaço interno com a arquitetura móvel do corpo, que envolve um alinhamento dinâmico do corpo, pois se está sempre em movimento de ajuste. É possível ainda pensar essa arquitetura interna em relação à arquitetura externa do espaço, o que é explanado no corpo do texto. Dito isso, percebe-se que o interno está em constante diálogo com o externo, seja a percepção interna e externa, o espaço interno e externo ou outras relações que se-jam significativas para o ator-bailarino.

Assim, encerramos o texto trazendo um grande tema do sistema LMA/BF, que é o interno-externo. Na dança, esta relação interno-externo produz simultaneamente um aporte para a otimização do esforço durante o movimento, tanto para o aspecto funcional de sua execução, quanto para sua expressão, estabelecida por meio da relação corpo-ambiente. Aqui, utilizamos outro dos grandes temas: função-expressão, para indicar que a funcionalidade de certos movimentos pode contar com o reconhecimento da linguagem espacial para a categoria Corpo, dando aporte para a expressão intrinsecamente relacionada à relação corpo-espaço-esforço.

O sistema Laban/Bartenieff produz incessantes modos de estabelecer relações entre suas categorias de análise, ajudando pesquisadores e artistas das artes da cena a aprimorar seus trabalhos artísticos por meio da integração dos conceitos, dos grandes temas, da necessária e funcional polarização de temas que se tornam frequentemente complementares em seus contrastes. Assim sendo, o espaço interno pode ser o reflexo perceptivo da relação corpo-espaço, ou corpo ambiente, com toda particularidade de cada ser humano, observada por certos critérios de análise aqui sugeridos; e pode ser a análise do corpo a partir de diferentes categorias de modo consciente, visando produzir a expressão necessária ao discurso da dramaturgia da cena.

\section{Referências}

ANDERSON, Jack. Ballet \& modern dance: a concise history. New Jersey/EUA: Princeton, 1992.

ANDRADE, Milton. Ação dramática, movimento funcional e teoria do esforço: origens do pensamento teatral na obra de Rudolf Laban. Revista Urdimento, Florianópolis, v. 2, n. 11, p. 169-176, 2008. Disponível em: http://www.revistas.udesc.br/index.php/ urdimento/article/view/1414573102112008169/8885. Acesso em: 03 out. 2018.

BARTENIEFF, Irmgard. Body movement: coping with the environment. Netherlands: Gordon and Breach Science Publishers, 1980.

DOWD, Irene. Taking root to fly. Nova York/EUA: Contact editions, 1995.

FERNANDES, Ciane. O corpo em movimento: o sistema Laban/Bartenieff na formação e pesquisa em artes cênicas. São Paulo: Annablume, 2006. 
HACKNEY, Peggy. Making Connections.Total Body integration Through Bartenieff Fundamentals. New York: Routledge, 2002.

LABAN, Rudolf. Domínio do Movimento. 4ª edição. São Paulo: Summus, 1978.

LABAN, Rudolf. The language of Movement: a guidebook to choreutic. Boston, EUA: Macdonald and Evans Ltd, 1966.

LOUPPE, Laurence. Poética da dança contemporânea. Lisboa: Orfeu Negro, 2012.

MARQUES, I. Revisitando a dança educativa moderna de Rudolf Laban. Sala Preta, São Paulo, v. 2, p. 276-281, 2011. Disponível em: http://www.revistas.usp.br/salapreta/ article/view/57104. Acesso em: 30 set. 2018.

MCHOSE, Caryn. Phenomenological Space: I'm in the space and the space is in me - interview with Hubert Godard. Contact Quarterly, Northampton, v. 31, p. 32-38, summer/fall 2006.

MIRANDA. Regina. Corpo-Espaço. Aspectos de uma geofilosofia do corpo em movimento. Rio de Janeiro: 7 Letras, 2008.

MÖDINGER, Carlos; SANTOS, Cristina; VALLE, Flavia; LOPONTE, Luciana. Práticas pedagógicas em artes: espaço, tempo e corporeidade. Erechim: Edelbra, 2012.

SASTRE, Cibele. ESPAÇOS DE AÇÃO E DE INSCRIÇÃO DE SI. In: Memória ABRACE XVI - Anais do IX Congresso da Associação Brasileira de Pesquisa e Pós-Graduação em Artes Cênicas. Anais. Uberlândia (MG) UFU, 2017. Disponível em: <https//www.even3. com.br/anais/IXCongressoABRACE/32721-ESPACOS-DE-ACAO-E-DE-INSCRICAO-DE-SI>. Acesso em: 27 maio 2019.

VALLE, Flavia. Respiração na Dança. Revista da Fundarte, Montenegro, v.IV, n.8, p.55 $-58,2004$.

Recebido em: 04/05/2019

Aprovado em: 24/01/2020 